\title{
Serum Concentrations of Selected Heavy Metals in Patients with Alcoholic Liver Cirrhosis from the Lublin Region in Eastern Poland
}

\author{
Andrzej Prystupa ${ }^{1}$, Anna Błażewicz ${ }^{2}$, Paweł Kiciński ${ }^{3,+}{ }^{+}$Jarosław J. Sak ${ }^{4,5,+, *}$, \\ Jarosław Niedziałek ${ }^{6,+}$ and Wojciech Załuska ${ }^{5}$ \\ 1 Department of Internal Medicine, Medical University of Lublin, Staszica 16, 20-081 Lublin, Poland; \\ aprystup@wp.pl \\ 2 Department of Analytical Chemistry, Medical University of Lublin, Chodźki 4a (Collegium \\ Pharmaceuticum), 20-093 Lublin, Poland; anna.blazewicz@umlub.pl \\ 3 Department of Family Medicine, Medical University of Lublin, Staszica 11, 20-081 Lublin, Poland; \\ pawelkici@wp.pl \\ 4 Department of Ethics and Human Philosophy, Medical University of Lublin, Staszica 4/6 (Collegium \\ Maximum), 20-059 Lublin, Poland \\ 5 Department of Nephrology, Medical University of Lublin, Jaczewskiego 8, 20-954 Lublin, Poland; \\ wtzaluska2@poczta.onet.pl \\ 6 Individual Medical Practice, Lublin, Ludwika Hirszfelda 5/11, 20-092 Lublin, Poland; \\ niedzialek.jarek@poczta.fm \\ * Correspondence: jareksak@tlen.pl; Tel.: +48-814-486-850 \\ + These authors contributed equally to this work.
}

Academic Editor: Icro Maremmani

Received: 12 March 2016; Accepted: 25 May 2016; Published: 13 June 2016

\begin{abstract}
According to the WHO report, alcohol is the third most significant health risk factor for the global population. There are contrary reports about heavy metals concentrations in patients with alcoholic liver cirrhosis. The aim of this study was to investigate serum concentrations of selected heavy metals in patients with alcoholic liver cirrhosis living in the eastern part of Poland according to cirrhosis stage. The participants came from various hospitals of the Lublin region were enrolled. The study group included 46 male and 16 female patients. The control group consisted of 18 healthy individuals without liver disease. High Performance Ion Chromatography was used to determine the concentrations of metal ions ( $\mathrm{Cd}, \mathrm{Zn}, \mathrm{Cu}, \mathrm{Ni}, \mathrm{Co}, \mathrm{Mn}$, and $\mathrm{Pb}$ ) in serum samples. The concentrations of copper, zinc, nickel, and cobalt were found to be significantly lower in patients with alcoholic liver cirrhosis compared to the control group. The serum concentration of cadmium was significantly higher in patients with advanced alcoholic liver cirrhosis compared to the control group. We hypothesize that disorders of metabolism of heavy metals seem to be the outcome of impaired digestion and absorption, which are common in cirrhosis, improper diet, environmental and occupational exposure.
\end{abstract}

Keywords: liver cirrhosis; alcohol; heavy metals; microelements

\section{Introduction}

According to the World Health Organization's report, alcohol is the third most significant health risk factor for the global population [1]. Chronic alcohol intake is associated with an increased risk of malnutrition, chronic pancreatitis, alcoholic liver disease (steatosis, hepatitis, cirrhosis), and cancer [2]. Liver cirrhosis is characterized by diffuse fibrosis of the hepatic connective tissue, which causes deterioration of its structure, degeneration and destruction of hepatocytes. 
Exposure to inappropriate doses of heavy metals results in several adverse health effects [3]. The role of heavy metals in the pathogenesis of liver cirrhosis and its complications is not fully understood. Heavy metals may exacerbate liver damage (e.g., lead, cadmium) but some of them are essential for the organism (microelements, e.g., cobalt, zinc). There are contrary reports about heavy metals concentrations in patients with alcoholic liver cirrhosis.

The aim of this study was to investigate serum concentrations of selected heavy metals in patients with alcoholic liver cirrhosis living in the eastern part of Poland according to cirrhosis stage and to compare them with concentrations in controls.

\section{Experimental Section}

\subsection{Patients}

Patients with alcoholic liver cirrhosis treated in various hospitals of the Lublin region were randomly enrolled. The study group included 46 male and 16 female patients, aged $54.9 \pm 10.4$ years. All patients presented a history of heavy alcohol consumption (mainly vodka and cheap wine) in the absence of positivity for serological markers of viral, autoimmune, and metabolic diseases. The diagnosis of liver cirrhosis was based on clinical features, laboratory tests and abdominal ultrasound. The Child-Turcotte-Pugh criteria (Child-Pugh score) as P-Ch A, P-Ch B, P-Ch C, were used to assess the severity of liver cirrhosis. The control group consisted of 18 (12 male and six female) healthy individuals, aged $43.7 \pm 14.6$ years, without liver disease and without a history of alcohol abuse. The exclusion criteria were tobacco smoking and vitamin and mineral supplements taken over the last three months, acute kidney damage, stage III-V chronic kidney disease, and acute infections. Characteristics of the study population are given in Tables 1 and 2.

The study design was approved by the Bioethics Committee of the Medical University of Lublin (agreement number KE-0254/190/2011). All subjects gave their written informed consent.

Table 1. Characteristics of the control and study group.

\begin{tabular}{|c|c|c|}
\hline Variables & Control Group $(n=18)$ & Study Group $(n=62)$ \\
\hline Age (years) & $43.7 \pm 14.6$ & $54.9 \pm 10.4$ \\
\hline Percentage of males (\%) & $67 \%$ & $74 \%$ \\
\hline Alcohol abuse (years) & - & $14.05 \pm 5.17$ \\
\hline Body Wright (kg) & $67.5 \pm 8.8$ & $68.7 \pm 13.7$ \\
\hline Total bilirubin (mg/dL) & $0.59 \pm 0.29$ & $5.33 \pm 7.07$ \\
\hline Albumin (g/dL) & $5.24 \pm 0.55$ & $2.63 \pm 0.66$ \\
\hline INR & $1.24 \pm 0.15$ & $1.52 \pm 0.35$ \\
\hline Total protein $(\mathrm{g} / \mathrm{dL})$ & $6.2 \pm 0.31$ & $5.6 \pm 0.84$ \\
\hline $\operatorname{ALT}(\mathrm{U} / \mathrm{L})$ & $17.9 \pm 5.9$ & $64.3 \pm 123.8$ \\
\hline AST (U/L) & $18.2 \pm 7.1$ & $115.5 \pm 166.5$ \\
\hline PLT (G/L) & $231.3 \pm 29.8$ & $133.7 \pm 73.9$ \\
\hline $\mathrm{MCV}(\mathrm{fL})$ & $84.7 \pm 3.4$ & $93.7 \pm 9.3$ \\
\hline Urea $(\mathrm{mg} / \mathrm{dL})$ & $24.5 \pm 10.1$ & $32.4 \pm 26.1$ \\
\hline Sodium (mmol/L) & $140 \pm 3.2$ & $134.3 \pm 5.4$ \\
\hline Potassium (mmol/L) & $4.3 \pm 0.39$ & $3.8 \pm 0.65$ \\
\hline CRP (mg/L) & $2.51 \pm 2.29$ & $21.07 \pm 10.96$ \\
\hline \multicolumn{3}{|c|}{ Complications } \\
\hline Oesophageal varices (\%) & - & $53 \%$ \\
\hline Ascitis (\%) & - & $42 \%$ \\
\hline Encephalopathy (\%) & - & $64 \%$ \\
\hline
\end{tabular}

Reference ranges provided by the laboratory that performed determinations: total bilirubin $(0-1.2 \mathrm{mg} / \mathrm{dL})$, albumin (3.5-5.2 g/dL), total protein (6-8 g/dL), ALT—alanine aminotransferase (5-40 U/L), AST—aspartate aminotransferase (5-40 IU/L), urea (21-43 mg/dL), PLT-blood platelets $(120-400 \mathrm{~K} / \mu \mathrm{L})$, INR-International Normalized Ratio (0.86-1.30), MCV-mean cell volume (80-94 fL), Na-sodium (136-145 mmol/L), K-potassium (3.5-5.1 mmol/L), CRP-C-reactive protein $(<5 \mathrm{mg} / \mathrm{L})$. 
Table 2. Concentrations of heavy metals in the control group and patients with various stages of liver cirrhosis according to Child-Pugh classification.

\begin{tabular}{cccccc}
\hline Heavy Metals & Controls & P-Ch A $(n=19)$ & P-Ch B $(n=20)$ & P-Ch C $(n=23)$ & $p^{*}$ \\
\hline Cadmium $(\mathrm{Cd})(\mathrm{mg} / \mathrm{L})$ & $0.0054 \pm 0.0007$ & $0.0061 \pm 0.0028$ & $0.0076 \pm 0.0045$ & $0.0078 \pm 0.0044$ & $<0.05$ \\
\hline Cobalt $(\mathrm{Co})(\mathrm{mg} / \mathrm{L})$ & $0.0042 \pm 0.0020$ & $0.0028 \pm 0.0016$ & $0.0026 \pm 0.0015$ & $0.0024 \pm 0.0014$ & $<0.01$ \\
\hline Copper $(\mathrm{Cu})$ & $1.2663 \pm 0.0771$ & $1.1178 \pm 0.2240$ & $1.1080 \pm 0.2024$ & $1.1529 \pm 0.1559$ & $<0.001$ \\
\hline Manganese $(\mathrm{Mg})(\mathrm{mg} / \mathrm{L})$ & $0.0089 \pm 0.0006$ & $0.0126 \pm 0.021$ & $0.0144 \pm 0.0214$ & $0.0154 \pm 0.0158$ & $\mathrm{NS}$ \\
\hline Zinc $(\mathrm{Zn})(\mathrm{mg} / \mathrm{L})$ & $1.3607 \pm 0.1123$ & $1.0371 \pm 0.3373$ & $0.9579 \pm 0.2441$ & $1.0095 \pm 0.3164$ & $<0.001$ \\
\hline Nickel $(\mathrm{Ni})(\mathrm{mg} / \mathrm{L})$ & $0.0019 \pm 0.001$ & $0.0007 \pm 0.001$ & $0.0005 \pm 0.001$ & $0.0003 \pm 0.0011$ & 0.0001 \\
\hline Lead $(\mathrm{Pb})(\mathrm{mg} / \mathrm{L})$ & $0.0384 \pm 0.0076$ & $0.0447 \pm 0.0135$ & $0.0439 \pm 0.0127$ & $0.0478 \pm 0.0176$ & $\mathrm{NS}$ \\
\hline Iron $(\mathrm{Fe})(\mathrm{mg} / \mathrm{L})$ & $1.3682 \pm 0.1452$ & $1.2288 \pm 0.2272$ & $1.3540 \pm 0.3264$ & $1.3170 \pm 0.2687$ & $\mathrm{NS}$ \\
\hline
\end{tabular}

NS-not significant $(p>0.05) .{ }^{*}$ Results of tests of intergroup multiple comparisons are presented in figures.

\subsection{Blood Samples}

The material for the study was the peripheral blood obtained from the ulnar vein. Blood samples were collected after an 8-12-h overnight fast between 8.00 and 10.00 a.m. into clot tubes, $7 \mathrm{~mL}$ in volume. Serum was separated by centrifugation at $1000 \mathrm{rpm}$ for $10 \mathrm{~min}$. Serum samples taken from healthy subjects and alcoholic liver cirrhosis patients were pre-treated and analyzed in the same way. They were transported and stored frozen at $-20^{\circ} \mathrm{C}$ in polypropylene containers. $1 \mathrm{~mL}$ of the sample was divided into two parts (each $0.5 \mathrm{~mL}$ ) in order to have two independent solutions prior to the mineralization procedure. The mineralization procedure was carried out in the NovaWave Microwave Tunnel Digestion System (Scp Science, Montreal, QC, Canada) using Teflon ${ }^{\circledR}$ vessels.

Each time an acidic digestion with $99 \%$ nitric acid water solution was applied $\left(1 \mathrm{~mL}\right.$ of $\mathrm{HNO}_{3}$ : $9 \mathrm{~mL} \mathrm{H}_{2} \mathrm{O}$ ). The conditions of the mineralization procedure had been previously optimized [4]. The obtained solutions were poured into volumetric flasks (PTFE).

The detailed procedure of preparation of standard solutions, operating HPIC conditions, and validation of the methods applied were described in the previous papers [4,5]. The limits of detection $(\mathrm{LOD})$ values (in $\mu \mathrm{g} / \mathrm{mL}$ ) were as follows: $0.022(\mathrm{Cd}), 0.026(\mathrm{Co}), 0.048(\mathrm{Cu}), 0.006(\mathrm{Mn}), 0.056(\mathrm{Zn})$, $0.006(\mathrm{Ni}), 0.009(\mathrm{Fe})$, and $0.0008(\mathrm{~Pb})$. The method accuracy was verified by the certified reference material (human serum): Seronorm ${ }^{\mathrm{TM}}$ Trace Elements Serum L-2 (Billingstad, Norway).

\subsection{Instrumentation and Reagents}

High Performance Ion Chromatography (HPIC) was used to determine concentrations of metal ions in serum samples.

A Dionex DX-500 ion chromatograph (Sunnyvale, CA, USA) composed of an IP25 isocratic pump, a pre-column IonPac CG5A, an IonPac CS5A column, and a AD20 UV-VIS detector was used for measurements. A Chromeleon (Dionex, Sunnyvale, CA, USA) chromatography workstation was used for instrument control and data acquisition. Post column reagent (PCR) was applied for the spectrophotometric detection. One liter of PCR was prepared with 0.5 mmole of 4-(2-pyridylazo)resorcinol (PAR), 1.0 mole of 2-dimethylamino-ethanol, 0.3 mole of sodium bicarbonate, and 0.50 mole of ammonium hydroxide dissolved in deionized water $(18 \mathrm{M} \Omega \cdot \mathrm{cm})$. All reagents were of analytical grade. The eluent was filtered and degassed before use. The pyridine-2,6-dicarboxylic acid (PDCA) eluent enables the separation of copper, nickel, zinc, cobalt, cadmium, and manganese. The composition of $1 \mathrm{~L}$ of the PDCA eluent concentrate (simplifying eluent preparation and improves reproducibility), which was five times diluted with deionized water and used as a mobile phase during chromatographic analysis, was as follows: $7.0 \mathrm{mmole}$ of PDCA, $66 \mathrm{mmole}$ of potassium hydroxide, $5.6 \mathrm{mmole}$ of potassium sulfate, and $74 \mathrm{mmole}$ of formic acid. The oxalic acid eluent concentrate (10 times diluted with deionized water) was used as a mobile phase during determinations of lead 
ions. The composition of the oxalic eluent was as follows: $8.0 \mathrm{mM}$ oxalic acid, $50 \mathrm{mM}$ potassium hydroxide, and $100 \mathrm{mM}$ tetramethylammonium hydroxide.

All mobile phase components were obtained from Sigma-Aldrich, Darmstatd, Germany. Aqueous solutions of metal salts were prepared by dilution of Titrisol standard metal salt solutions (Merck Millipore, Darmstadt, Germany). PAR was obtained from Dionex, Sunnyvale, CA, USA.

All analyses were carried out using pre-washed polypropylene flasks and vials.

\subsection{Statistical Analysis}

STATISTICA 10 PL (StatSoft, Inc., Tulsa, OK, USA) was used for statistical analysis. Continuous variables were expressed as mean \pm standard deviation (SD). Before analysis, variables were checked for normality using the Shapiro-Wilk test; the Brown-Forsythe test was applied to test equality of variances. Variables were compared using the $t$-student test or ANOVA test when normally distributed or Mann-Whitney test or Kruskall-Wallis test, when non-normally distributed. Analysis of covariance (ANCOVA) was performed to examine differences between groups representing the controls and the patients with the consecutive stages of cirrhosis on a heavy metal concentration after controlling for variation of age (considered to be a nuisance variable). Correlations between two variables were analyzed with the Pearson correlation coefficient or Spearman's rank correlation coefficient when appropriate. For all tests, $p<0.05$ was considered as statistically significant.

\section{Results}

\subsection{Concentrations of Heavy Metals in Patients with Alcoholic Liver Cirrhosis Compared to the Control Group}

Serum concentrations of heavy metals in controls and patients with various stages of alcoholic liver cirrhosis were presented in Table 2 and in Figures 1-5.

Significant differences in cadmium concentrations were observed in the study population (Figure 5); the concentrations in question were significantly lower in the control group $(0.0054 \pm 0.0007 \mathrm{mg} / \mathrm{L})$ than in patients with advanced cirrhosis, i.e., in Child-Pugh $C$ patients $(0.0078 \pm 0.0044 \mathrm{mg} / \mathrm{L})$. Moreover, copper concentrations were significantly higher in the control group $(1.2663 \pm 0.0771 \mathrm{mg} / \mathrm{L})$ compared to Child-Pugh A $(1.1178 \pm 0.2240 \mathrm{mg} / \mathrm{L}), \mathrm{B}(1.1080 \pm 0.2024 \mathrm{mg} / \mathrm{L})$, and C (1.1529 \pm 0.1559$)$ patients. Otherwise, there were no significant differences in its concentrations among patients with various stages of cirrhosis (Figure 2). Concentrations of zinc were significantly lower in Child-Pugh A $(1.0371 \pm 0.3373 \mathrm{mg} / \mathrm{L}), \mathrm{B}(0.9579 \pm 0.2441 \mathrm{mg} / \mathrm{L})$, and C $(1.0095 \pm 0.3164)$ patients compared to controls (1.3607 $\pm 0.1123 \mathrm{mg} / \mathrm{L}$ ) (Figure 3). Similarly to copper, there were no significant differences in its concentrations among subgroups with different stages of cirrhosis. Furthermore, concentrations of nickel were significantly higher in the control group $(0.0019 \pm 0.001 \mathrm{mg} / \mathrm{L})$ compared to Child-Pugh $\mathrm{B}(0.0005 \pm 0.001 \mathrm{mg} / \mathrm{L})$ and $\mathrm{C}(0.0003 \pm 0.0011 \mathrm{mg} / \mathrm{L})$ patients (Figure 4). Serum concentrations of cobalt were significantly lower in Child-Pugh B $(0.0026 \pm 0.0015 \mathrm{mg} / \mathrm{L})$ and C $(0.0024 \pm 0.0014)$ patients compared to controls $(0.0042 \pm 0.0020 \mathrm{mg} / \mathrm{L})$ (Figure 1).

An increasing trend in concentrations of manganese and lead was observed in patients with cirrhosis, yet the elevations were not statistically significant (Table 2). There were no significant inter-subgroup differences in iron concentrations (Table 2).

Additionally, analysis of covariance (ANCOVA) confirmed that there was a significant effect of the independent variable (i.e., "subgroup", which divides the population into four categories: healthy, and alcoholics with classes A, B, and C of liver cirrhosis,) on serum concentration of cadmium, copper, zinc, nickel, and cobalt after controlling for the effect of age (considered to be a confounding factor). 


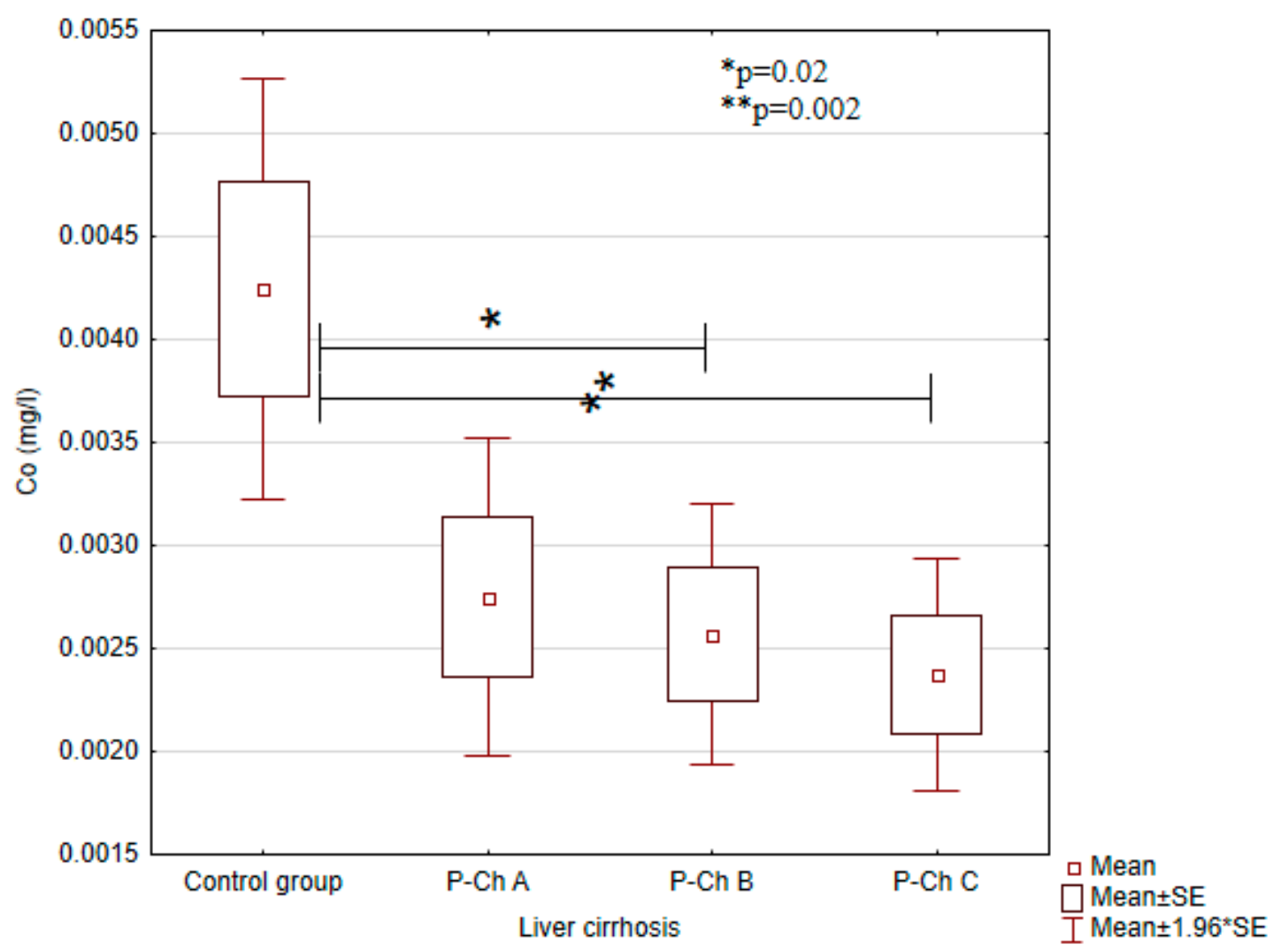

Figure 1. Concentrations of cobalt in individual subgroups.

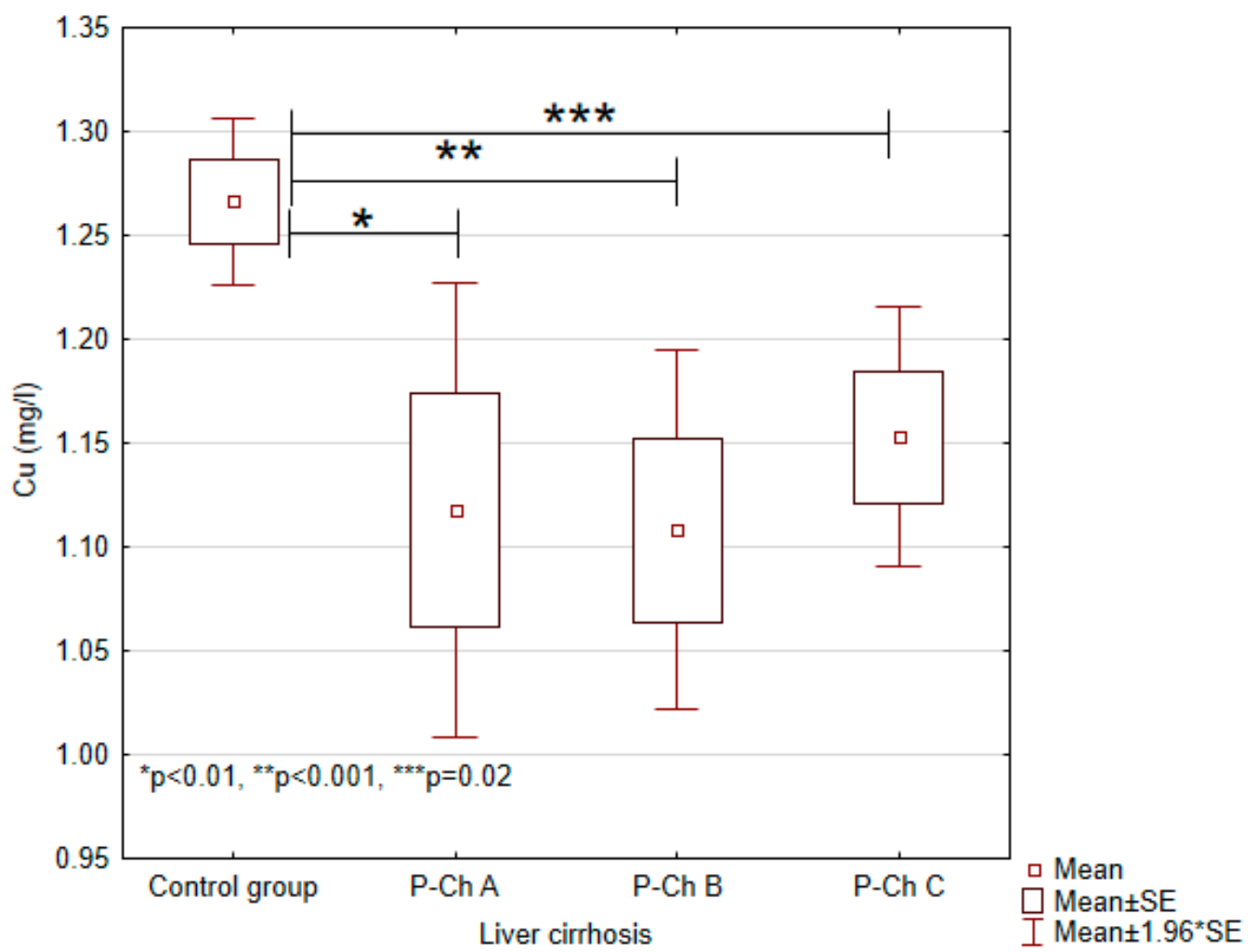

Figure 2. Concentrations of copper $(\mathrm{Cu})$ in individual subgroups. 


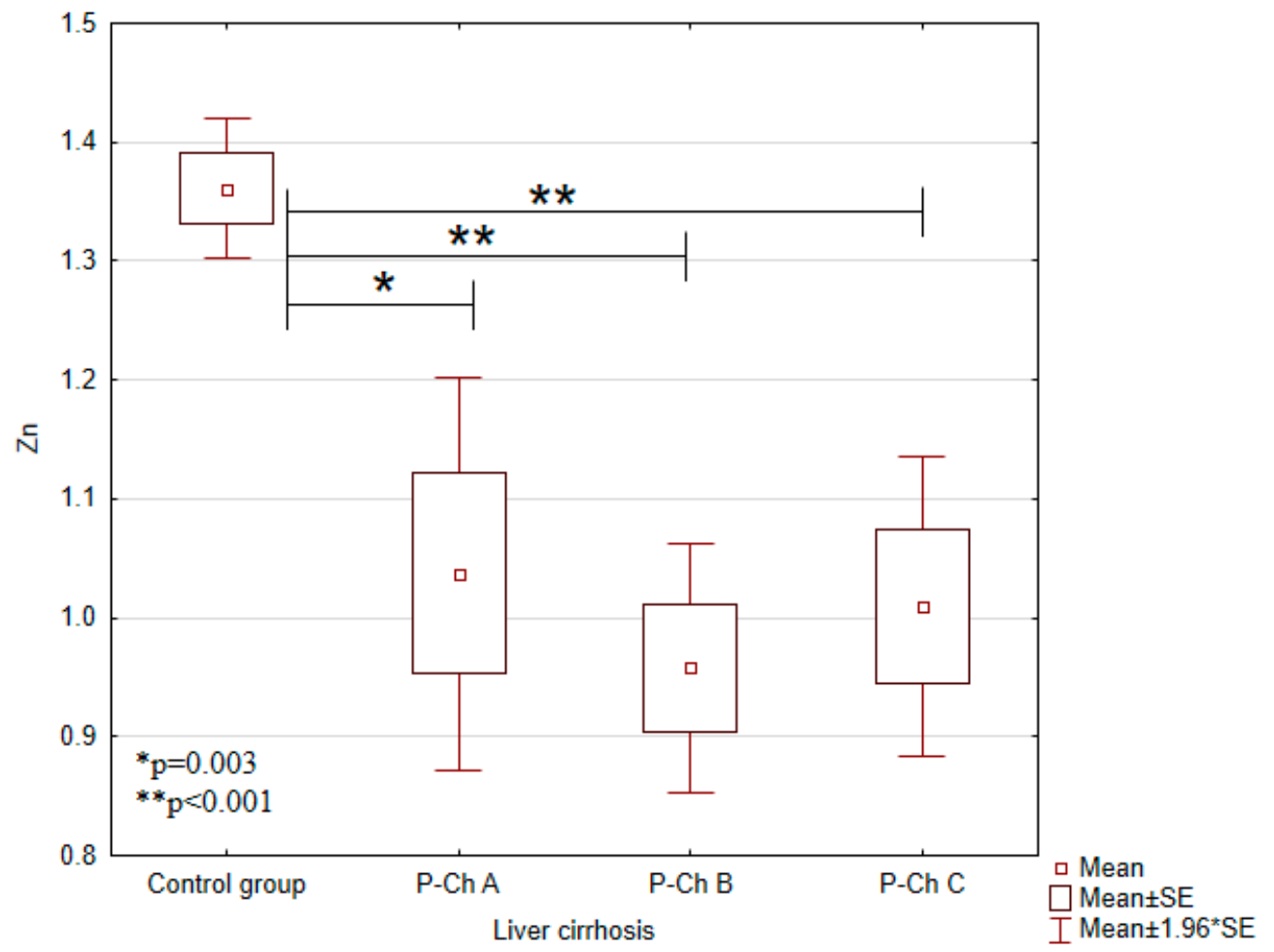

Figure 3. Concentrations of zinc (Zn) in individual subgroups.

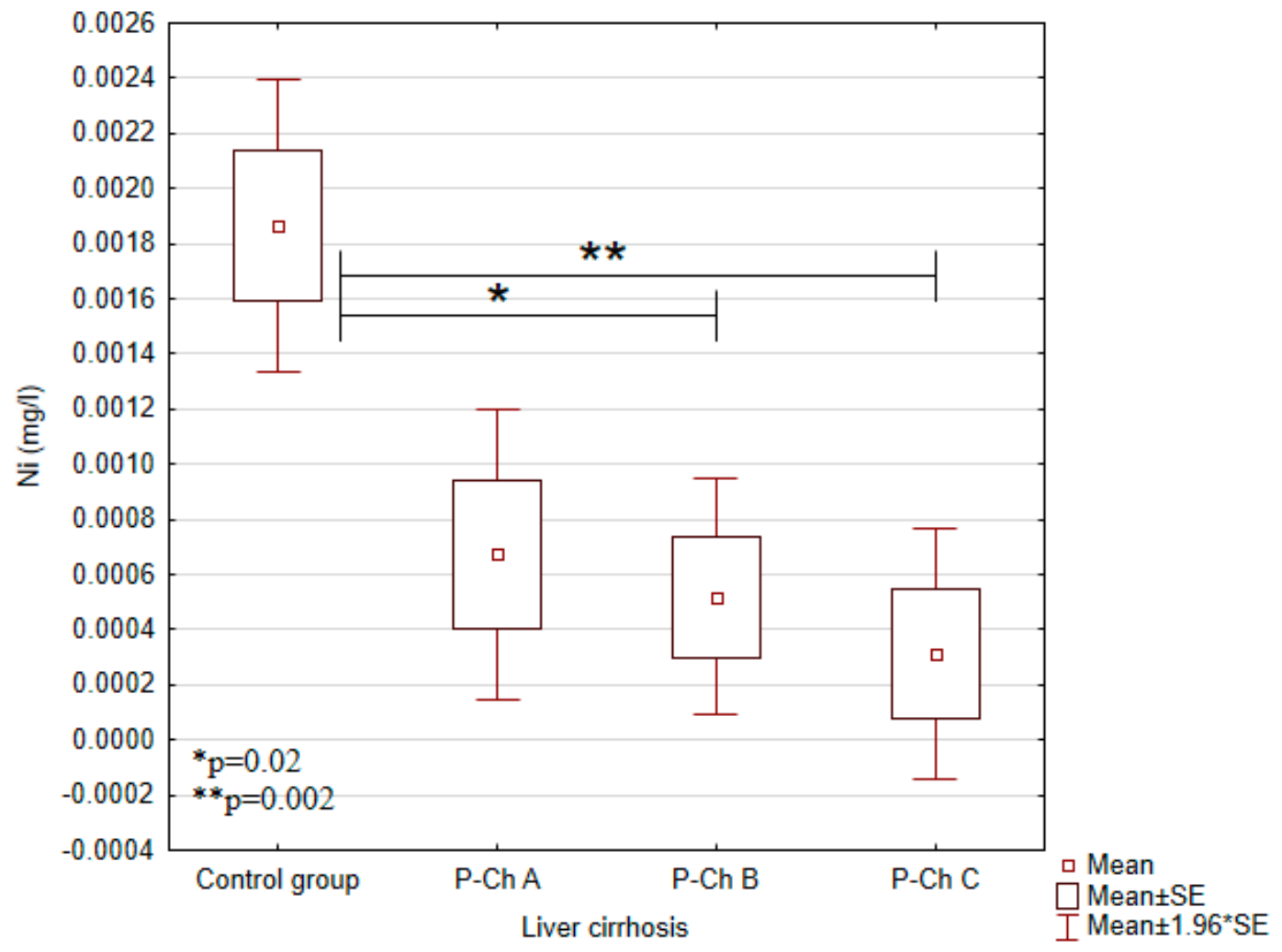

Figure 4. Concentrations of nickel (Ni) in individual subgroups. 


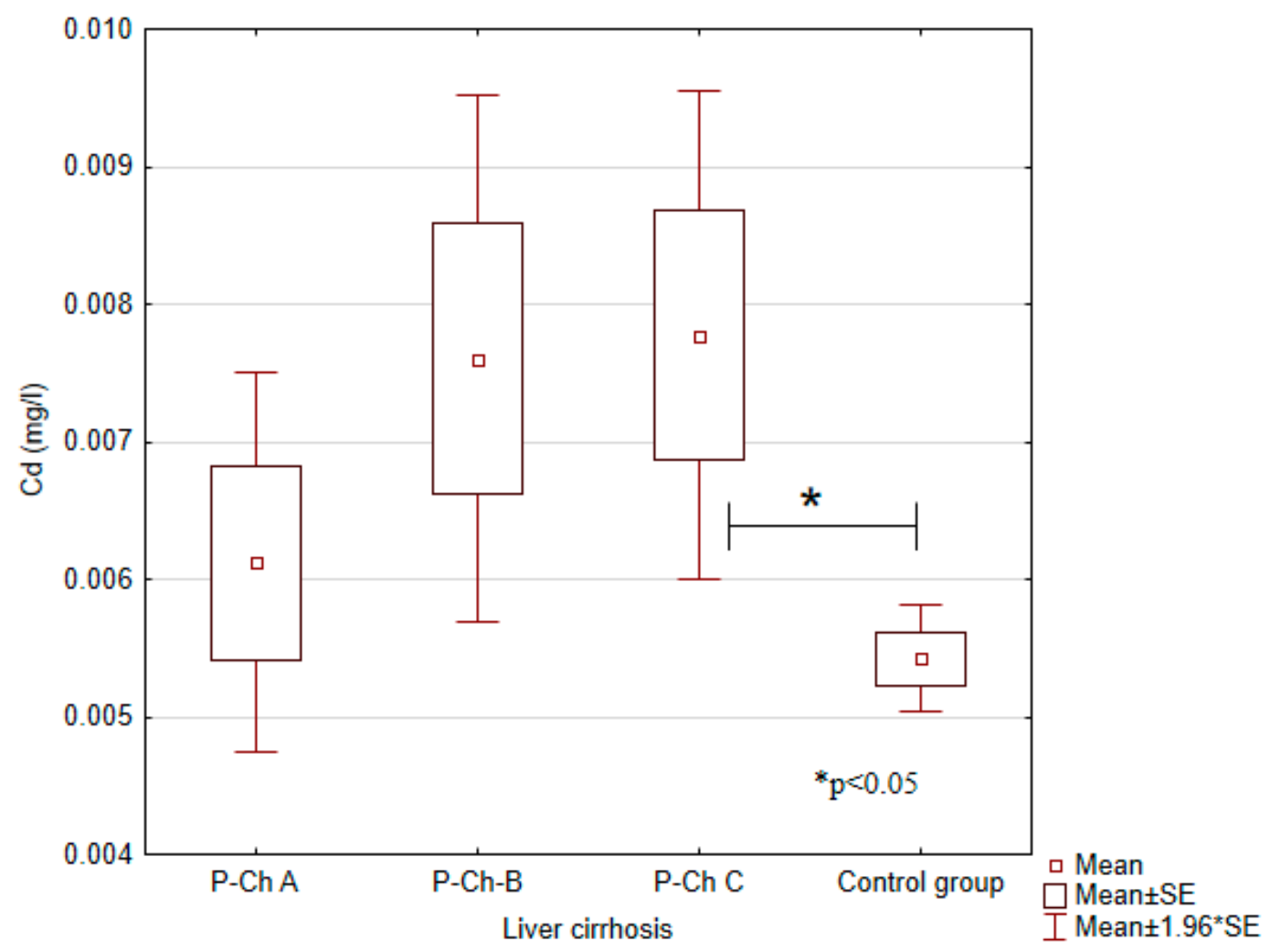

Figure 5. Concentrations of cadmium (Cd) in individual subgroups.

\subsection{Correlations between Heavy Metal Concentrations and Age, Gender, and Duration of Alcohol Abuse}

The Spearman's rank correlation test demonstrated that duration of alcohol abuse was negatively correlated with concentrations of cobalt $(\mathrm{r}=-0.33, p<0.01)$, copper $(\mathrm{r}=-0.29, p=0.01)$, zinc $(\mathrm{r}=-0.3$, $p=0.01)$, and nickel ( $r=-0.47, p<0.0001)$. A significant, albeit weak, correlation was found between age versus the concentration of cadmium $(\mathrm{r}=0.23, p<0.05)$ and lead $(\mathrm{r}=0.24, p<0.05)$. No significant correlations were observed between concentrations of the heavy metals studied and gender.

\subsection{Correlations between Concentrations of Heavy Metals and Laboratory Results}

Moderate positive correlations were demonstrated between the platelet count versus concentrations of zinc $(\mathrm{r}=0.34, p<0.01)$ and nickel $(\mathrm{r}=0.48, p<0.0001)$, and a negative correlation between the platelet count and concentration of cadmium $(\mathrm{r}=-0.28 ; p<0.05)$. Otherwise, concentrations of cobalt were negatively correlated with MCV $(\mathrm{r}=-0.36, p=0.001)$. Moreover, the AST activity was negatively correlated with concentrations of cobalt $(\mathrm{r}=-0.35, p<0.01)$, zinc $(\mathrm{r}=-0.29 ; p<0.05)$, and nickel $(\mathrm{r}=-0.24, p<0.05)$ while the concentration of total bilirubin was negatively correlated with the concentration of nickel ( $\mathrm{r}=-0.24 ; p<0.05)$. The International Normalized Ratio (INR) value was negatively correlated with the concentration of nickel $(\mathrm{r}=-0.47 ; p<0.001)$. Furthermore, a negative correlation was found between the concentration of $C$-reactive protein (CRP) and concentrations of cobalt $(\mathrm{r}=-0.26 ; p<0.05)$ and copper $(\mathrm{r}=-0.27 ; p<0.05)$.

3.4. Concentrations of Heavy Metals according to the Presence of Ascitis, Encephalopathy, and Esophageal Varices

The concentration of nickel was demonstrated to be significantly lower in patients with ascites as compared to cirrhotic patients without ascites $(0.0003 \pm 0.001$ vs. $0.0007 \pm 0.001 \mathrm{mg} / \mathrm{L} ; p<0.05)$. Concentrations of zinc and nickel were lower in patients with esophageal varices as compared to 
cirrhotic patients without esophageal varices $(0.0003 \pm 0.008$ vs. $0.0007 \pm 0.001 \mathrm{mg} / \mathrm{L} ; p<0.05$ and $0.958 \pm 0.304$ vs. $1.048 \pm 0.294 ; p<0.05$, respectively).

\subsection{Correlations among Heavy Metal Concentrations}

A significant correlation was demonstrated between concentrations of cadmium and manganese $(\mathrm{r}=0.48 ; p<0.0001)$, cobalt and nickel $(\mathrm{r}=0.29 ; p<0.05)$, copper and zinc $(\mathrm{r}=0.3 ; p<0.05)$, as well as zinc and nickel $(\mathrm{r}=0.39 ; p<0.001)$.

\section{Discussion}

"Heavy metals" is an imprecise term that involves a variously-defined collection of metals and semimetals characterized by high density. Our study presents analysis of serum concentrations of the selected heavy metals in patients with alcoholic liver cirrhosis. Some of the metals studied play important biological roles as microelements necessary for proper activities of numerous enzymes and for other processes $(\mathrm{Cu}, \mathrm{Co}, \mathrm{Zn}, \mathrm{Fe}, \mathrm{Mn}, \mathrm{Ni})$. However, their excess can cause toxic effects. Moreover, $\mathrm{Cd}$ and $\mathrm{Pb}$ are toxic elements whose presence in the human body is unnecessary. The patients included to the study were from Lublin and its region (Southeastern Poland). The Lublin province is an agricultural, poorly-industrialized region, and our subjects were predominantly farmers and unemployed individuals; thus, the potential effect of environmental and occupational exposure was minimized.

Our study findings demonstrated a significant increase in serum concentrations of cadmium in P-Ch C patients compared to controls. The major sources of this element in the body are environmental (including cigarette smoke) and occupational exposures. Cadmium is predominantly absorbed via the respiratory and digestive route, as well as the skin, although to a markedly lesser degree, and accumulates mainly in the kidneys and liver, where it exerts its toxic effects [6,7]. Chronic exposure to cadmium has been demonstrated to lead to hepatocyte damage [8]. Cadmium is an element of high toxicity and long half-life, which has negative effects on reproductive capacities and the cardiovascular system [9]. In humans, cadmium exerts carcinogenic effects affecting numerous cellular and molecular mechanisms (including redox imbalance, DNA repair, and inhibition of apoptosis) [10]. Kazi et al. have reported elevated concentrations of cadmium in patients with liver cirrhosis. Moreover, they have demonstrated significantly higher concentrations of cadmium in patients with HCC. However, their study regarded patients with liver cirrhosis induced by viral hepatitis and not alcoholic cirrhosis, as in our study; moreover, they did not analyze the effects of cirrhosis stage on concentrations of cadmium [11,12]. Further studies are required to assess the cause-effect relationship between elevated concentrations of cadmium and the development of HCC. Noteworthy, our findings revealed a correlation between the concentration of cadmium and reduced platelet count, which is likely to be of clinical importance.

Concentrations of cobalt were significantly lower in patients with alcoholic liver cirrhosis as compared to controls. Cobalt gets into the body in a few ways: firstly with food; secondly by the respiratory system; thirdly, by the skin. Cobalt is necessary for maintaining normal physiological functions of the human body. The organic form of cobalt is a component of vitamin B12 and is essential for formation of amino acids, some proteins in the nervous cells, and neurotransmitters [13]. Hunt $e$ al. have demonstrated significantly reduced concentrations of cobalt in the livers of subjects with cirrhosis [14]. Low serum concentrations of cobalt in patients with liver cirrhosis can result from malnutrition and impaired absorption.

Copper is an essential nutrient trace metal involved in a multitude of cellular processes. Copper is used as a cofactor in numerous enzymatic mechanisms [15]. Sawa et al. have showed that Cu levels in serum and liver tissues were significantly higher in patients with liver cirrhosis compared to the control group. The main pathway of $\mathrm{Cu}$ excretion is via the biliary tract. In patients with long-term obstructive jaundice or primary biliary cirrhosis, serum and hepatic $\mathrm{Cu}$ levels are increased [16]. Rahelic et al. have found that serum concentrations of copper were significantly higher in patients with alcoholic liver 
cirrhosis in comparison to controls [17]. In our study, serum concentrations of copper were significantly lower in patients with liver cirrhosis compared to controls. Low concentrations of copper in the study group might have resulted from impaired absorption and malnutrition. Our results are consistent with the study by Fields et al. who demonstrated in animal model that alcohol consumption may aggravate copper deficiency [18].

Nickel results in increased levels of aspartate aminotransferase (AST), alanine aminotransferase (ALT) and gamma-glutamyl-transpeptidase (SGGT) in the liver and serum of animals and humans exposed to nickel salts [19]. Volini et al. have reported significantly increased hepatic concentrations of nickel in the early and advanced stages of hepatic cirrhosis [20]. In our study, serum concentrations of nickel were significantly lower in patients with liver cirrhosis compared to controls. Similar results were reported by McNeely et al. Serum concentrations of nickel were found to be significantly lower in 18 patients with liver cirrhosis compared to controls. According to the authors, decreased levels of serum nickel in liver cirrhosis may reflect diminished concentrations of serum nickeloplasmin and albumin [21]. Absorbed nickel is eliminated in the urine [22]. Patients with ascites in the course of liver cirrhosis are usually treated with diuretics. This may lead to increased excretion of nickel and its decreased serum level.

Liver plays an important role in maintaining systemic zinc homeostasis. In our study, the concentration of zinc was significantly lower in P-Ch A-C patients compared to controls. Several studies have concluded that zinc levels are decreased in serum of individuals with liver cirrhosis. Goode et al. have demonstrated that plasma zinc concentrations were reduced in patients with liver cirrhosis compared to controls and correlated strongly with plasma albumin concentrations [23]. Albumin is the major zinc carrier in the plasma and binds approximately $80 \%$ of plasma zinc [24]. Inadequate dietary intake, as well as the impaired absorption or increased clearance of zinc, may be responsible for the decrease of zinc content in patients with liver diseases [25]. Yoshida et al. measured serum Zn levels before and 60, 120, $180 \mathrm{~min}$ after administration of $\mathrm{Zn}$ sulfate. Lower increases in serum zinc levels 120 and $180 \mathrm{~min}$ after ingestion in cirrhotic patients than in controls indicated $\mathrm{Zn}$ malabsorption, which might be caused by portal hypertensive gastrocolonopathy [26]. Diuretic therapy in patients with cirrhosis and ascites results in increased renal zinc excretion [27]. Reding et al. have showed that short-term oral zinc supplementation improves hepatic encephalopathy by correcting zinc deficiency that compromises conversion of ammonia to urea [28].

In our study, serum levels of manganese and lead were higher in cirrhotic patients than those in controls but the differences were not statistically significant. Rahelic et al. have revealed that serum concentrations of manganese were significantly higher in patients with liver cirrhosis compared to the control group [17]. Moscarello has not found any significant difference in concentrations of manganese between cirrhotic patients and controls [29]. Manganese is secreted in bile, thus, its concentration increases in cholestatic liver disease [30]. According to Jurczyk et al., the mean value of serum iron did not differ significantly among patients with chronic viral hepatitis, alcoholic liver cirrhosis and alcoholic hepatitis [31].

\section{Conclusions}

Disorders of heavy metal metabolism seem to be the outcome of impaired digestion and absorption, which are common in cirrhosis, improper diet, environmental and occupational exposure.

Malnutrition is one of the essential liver cirrhosis-related problems [32]. Low serum concentrations of zinc, copper, cobalt, and nickel are most likely caused by inadequate dietary intake and malabsorption. Moreover, substantial effects of environmental exposure connected with work and place of residence cannot be excluded, which could, at least partially, explain the diverse results reported by various authors.

Further studies are needed to determine the prognostic value of impaired metabolism of heavy metals and effects of their supplementation on the clinical course of alcoholic liver cirrhosis. 
Acknowledgments: This study was supported by grants from Medical University of Lublin, Poland. Grant of the Medical University of Lublin No. DS 507/2013-2015.

Author Contributions: Andrzej Prystupa conceptualized the design and the data analysis, conducted the experimental procedure, interpreted the data and drafted and finalized the manuscript. Anna Błażewicz contributed to the design of the analysis, conducted the laboratory and statistical analysis and contributed to the draft manuscript. Paweł Kiciński, Jarosław J. Sak and Jarosław Niedziałek contributed to the design of the analysis and interpreted the data and contributed to the draft manuscript. Wojciech Załuska contributed to the draft manuscript. All authors read and approved the final manuscript.

Conflicts of Interest: The authors declare no conflict of interest.

\section{References}

1. World Health Organization. Global Health Risks: Mortality and Burden of Disease Attributable to Selected Major Risks; World Health Organization: Geneva, Switzerland, 2009.

2. Louvet, A.; Mathurin, P. Alcoholic liver disease: Mechanisms of injury and targeted treatment. Nat. Rev. Gastroenterol. Hepatol. Nat. Rev. Gastroenterol. Hepatol. 2015, 12, 231-242. [CrossRef] [PubMed]

3. Jaishankar, M.; Tseten, T.; Anbalagan, N.; Mathew, B.B.; Beeregowda, K.N. Toxicity, mechanism and health effects of some heavy metals. Interdiscip. Toxicol. 2014, 7, 60-72. [CrossRef] [PubMed]

4. Błażewicz, A.; Orlicz-Szczęsna, G.; Prystupa, A.; Szczęsny, P. Use of ion chromatography for the determination of selected metals in blood serum of patients with type 2 diabetes. J. Trace Elem. Med. Biol. 2010, 24, 14-19. [CrossRef] [PubMed]

5. Błażewicz, A.; Dolliver, W.; Sivsammye, S.; Deol, A.; Randhawa, R.; Orlicz-Szczęsna, G.; Błażewicz, R. Determination of cadmium, cobalt, copper, iron, manganese and zinc in thyroid glands of patients with diagnosed nodular goitre using ion chromatography. J. Chromatogr. B 2010, 878, 34-38. [CrossRef] [PubMed]

6. Madden, E.; Fowler, B. Mechanisms of nephrotoxicity from metal combinations: A review. Drug Chem. Toxicol. 2000, 23, 1-12. [CrossRef] [PubMed]

7. Czeczot, H.; Skrzycki, M. Cadmium-Element completely unnecessary for the organism. Postepy Hig. Med. Dośw. 2010, 64, 38-49.

8. Kang, M.-Y.; Cho, S.-H.; Lim, Y.-H.; Seo, J.-C.; Hong, Y.-C. Effects of environmental cadmium exposure on liver function in adults. Occup. Environ. Med. 2013, 70, 268-273. [CrossRef] [PubMed]

9. Türkcan, A.; Scharinger, B.; Grabmann, G.; Keppler, B.; Laufer, G.; Bernhard, D.; Messner, B. Combination of cadmium and high cholesterol levels as a risk factor for heart fibrosis. Toxicol. Sci. 2015, 145, 360-371. [CrossRef] [PubMed]

10. Waisberg, M.; Joseph, P.; Hale, B.; Beyersmann, D. Molecular and cellular mechanisms of cadmium carcinogenesis. Toxicology 2003, 192, 95-117. [CrossRef]

11. Kazi, T.; Kolachi, N.F.; Afridi, H.I.; Kazi, N.G.; Sirajuddin; Naeemullah; Arain, S.S. Effects of mineral supplementation on liver cirrhotic/cancer male patients. Biol. Trace Elem. Res. 2012, 150, 81-90. [CrossRef] [PubMed]

12. Kolachi, N.F.; Kazi, T.G.; Afridi, H.I.; Kazi, N.G.; Khan, S. Investigation of essential trace and toxic elements in biological samples (blood, serum and scalp hair) of liver cirrhotic/cancer female patients before and after mineral supplementation. Clin. Nutr. 2012, 31, 967-973. [CrossRef] [PubMed]

13. Czarnek, K.; Terpiłowska, S.; Siwicki, A.-K. Selected aspects of the action of cobalt ions in the human body. Cent. Eur. J. Immunol. 2015, 40, 236-242. [CrossRef] [PubMed]

14. Hunt, A.H.; Parr, R.M.; Taylor, D.M.; Trott, N.-G. Relation between cirrhosis and trace metal content of liver. Brit. Med. J. 1963, 14, 1498-1499. [CrossRef]

15. Gaetke, L.M.; Chow-Johnson, H.S.; Chow, C.K. Copper: Toxicological relevance and mechanisms. Arch. Toxicol. 2014, 88, 1929-1938. [CrossRef] [PubMed]

16. Sawa, A.; Okita, K. The role of copper and zinc as pathogenic factors in liver disease. In Trace Elements in Clinical Medicine; Tomita, H., Ed.; Springer: Tokyo, Japan, 1990; pp. 89-92.

17. Rahelić, D.; Kujundzić, M.; Romić, Z.; Brkić, K.; Petrovecki, M. Serum concentration of zinc, copper, manganese and magnesium in patients with liver cirrhosis. Coll. Antropol. 2006, 30, 523-528. [PubMed]

18. Fields, M.; Lewis, C.G. Alcohol consumption aggravates copper deficiency. Metabolism 1990, 39, 610-613. [CrossRef] 
19. Sidhu, P.; Gorg, M.L.; Morgenstern, P.; Vogt, J.; Butz, T.; Dhawan, D.K. Role of zinc in regulating the levels of hepatic elements following nickel toxicity in rats. Biol. Trace Element. Res. 2004, 102, 161-172. [CrossRef]

20. Volini, F.; de la Huerga, J.; Kent, G. Trace metal studies in the liver disease using atomic absorption spectrometry. In Laboratory Diagnosis of Liver Diseases; Sunderman, F.W., Sunderman, F.W., Jr., Eds.; Warren H. Green Inc.: St. Louis, MO, USA, 1968; p. 199.

21. McNeely, M.D.; Sunderman, F.W., Jr.; Nechay, M.-W.; Levine, H. Abnormal concentrations of nickel in serum in cases of myocardial infarction, stroke, burns, hepatic cirrhosis, and uremia. Clin. Chem. 1971, 17, 1123-1128. [PubMed]

22. Sunderman, F.W., Jr. Nickel. In Metals and Their Compounds in the Environment; Merian, E., Anke, M., Ihnat, M., Stoeppler, M., Eds.; Wiley-VCH Verlag GmbH \& Co. KGaA: Weinheim, Germany, 1991; pp. 841-867.

23. Goode, H.F.; Kelleher, J.; Walker, B.E. Relation between zinc status and hepatic functional reserve in patients with liver disease. Gut 1990, 31, 694-697. [CrossRef] [PubMed]

24. Lu, J.; Stewart, A.J.; Sadler, P.J.; Pinheiro, T.J.; Blindauer, C.A. Albumin as a zinc carrier: Properties of its high-affinity zinc-binding site. Biochem. Soc. Trans. 2008, 36, 1317-1321. [CrossRef] [PubMed]

25. McClain, C.; Su, L.C. Zinc deficiency in the alcoholic: A review. Alcohol Clin. Exp. Res. 1983, 7, 5-10. [CrossRef] [PubMed]

26. Adams, P.C.; Bradley, C.; Frei, J.V. Hepatic iron and zinc concentrations after portacaval shunting for nonalcoholic cirrhosis. Hepatology 1994, 19, 101-105. [CrossRef] [PubMed]

27. Barry, M.; Keeling, P.W.N.; Feely, J. Tissue zinc status and drug elimination in patients with chronic liver disease. Clin. Sci. 1990, 78, 547-551. [CrossRef] [PubMed]

28. Reding, P.; Duchateau, J.; Bataille, C. Oral zinc supplementation improves hepatic encephalopathy. Results of a randomised controlled trial. Lancet 1984, 8401, 493-495. [CrossRef]

29. Moscarella, S.; Duchini, A.; Buzzelli, G. Lipoperoxidation, trace elements and vitamin E in patients with liver cirrhosis. Eur. J. Gastroenterol. Hepatol. 1994, 6, 633-636. [CrossRef]

30. Krieger, D.; Krieger, S.; Jansen, O.; Gass, P.; Theilmann, L.; Lichtnecker, H. Manganese and chronic hepatic encephalopathy. Manganese and chronic hepatic encephalopathy. Lancet 1995, 8970, 270-274. [CrossRef]

31. Jurczyk, K.; Wawrzynowicz-Syczewska, M.; Boron-Kaczmarska, A.; Sych, Z. Serum iron parameters in patients with alcoholic and chronic cirrhosis and hepatitis. Med. Sci. Monit. 2001, 7, 962-965. [PubMed]

32. Kowala-Piaskowska, A.; Tomaszewska, A.; Adamek, A.; Bura, M.; Mozer-Lisiewska, I. Malnutrition in liver cirrhosis. Hepatology 2014, 14, 90-93. 